\title{
A Hub-based University Innovation Model
}

\author{
Samuel Prieto Mejia ${ }^{I^{*}}$, Juan Manuel Montes Hincapie ${ }^{2}$, John Alexander Taborda Giraldo
}

\begin{abstract}
This article uses a conceptual approach to propose an innovation model for regional universities. It demonstrates that the traditional university encounters several obstacles that hinder its full integration into the development of its respective region and explains why currently known models cannot adapt to regions that have deficient relationships with the government and lack an entrepreneurial base. The new model is based on a structure composed of units called "innovation hubs" and incorporates social innovation, thus permitting the university to become integrated into the regional innovation ecosystems. The Magdalena University in Colombia was used as a reference in developing the model.
\end{abstract}

Keywords: hub; social innovation; university innovation models; regional innovation ecosystems

Submitted: May $19^{\text {th }}, 2018 /$ Approved: January $28^{\text {th }}, 2019$

\section{Introduction}

Changes in demographics, society, and especially technology, which have been expressed through external demands, (Martin-Sardesai, Irvine, Tooley, \& Guthrie, 2017) require universities to reflect upon their need for transformation (Youtie \& Shapira, 2008) from the former model wherein they are seen as isolated producers of knowledge (Novoa, 2016) to an integrated one wherein they are understood to be part of a regional innovation ecosystem (Dedehayir, Ortt, \& Seppänen, 2017). General models such as the triple helix model propose the integration of the three main agents-business, government, and university-in the creation of regional innovation ecosystems (Sarpong, AbdRazak, Alexander, \& Meissner, 2017; Molina, Polanco, \& Montes, 2015). Other models based on this one have been proposed and adjusted to the specific characteristics of the Ibero-American region (Salazar, 2015); unfortunately, however, these models do not take into account difficulties involving the practicability of their implementation in regional universities located in settings that lack an entrepreneurial base and have insufficient relationships with the government. However, these regions do possess cultural, historical, touristic, and environmental resources that may potentially be exploited in order to allow universities to overcome the economic obstacles in the region and promote a partnership between the public and private sectors based on social innovation. (Rao-Nicholson, Vorley, \& Khan, 2017). One example of how social innovation may help promote the potential of a region is the "Saco Crea Project carried out by the government of Colombia in the municipality of Juan de Acosta, more specifically, in the township of San José de Saco, in the Department of de Atlantic (northern Colombia). Based on the knowledge and textile abilities of the inhabitants of the township, the government implemented the MUSA Association initiative in which 20 women from the community produce household items for several home interior stores in the city of Barranquilla" (Villa \& Melo, 2015, p.11); unfortunately, initiatives such as this one are scarce and sporadic.
This example highlights the necessity for the development of an innovative model for the regional university. This new model must envision the university as a "builder" of a relationship of trust with the local government and foster the creation of an entrepreneurial base by means of an active participation of the university community that takes advantage of the social potential of the region and allows both national and international agents to encounter adequate conditions for their integration into the region. This model should have a "bottom-up" focus, that is, the individuals from the region, with support from the university, are the ones who generate innovations that allow various actors to be summoned to the elaboration of high-impact solutions that consolidate confidence in the local governments or plant seeds for the construction of an entrepreneurial base.

The novelty of this model must not be derived from merely theoretical approaches, but instead must be based upon the practical experiences of technological and social innovation units that are currently in operation and have become very popular on the international scene. However, the model must be complemented by theoretical principles so that it may be used as a reference for regional universities.

This conceptual study proposes an innovative model for the regional university that is based on the concepts of social innovation, fractal organization theory, systems, networks, and technological and social innovation hubs.

This model developed in this work is based on a case study of the University of Magdalena, due to both its ongoing efforts to become an innovative university and its regional nature, being located in a region that has a sparse entrepreneurial base and lacks sufficient aid from government organizations with regard to innovation.

(1) University of Magdalena, Santa Marta, Colombia.

(2) University of Medellin, Medellin, Colombia.

"Corresponding Author: sprieto@unimagdalena.edu.co 


\section{Theoretical Background}

\section{Social Innovation}

"Social innovation is defined as the implementation of programs and initiatives that possess characteristics related to providing a solution to a social, environmental, or cultural problem in a way that is novel and more effective, efficient, sustainable, or just than those already in existence; this solution may take the form of a product, process, technology, regulation, intervention, or social movement, may come from any sector of society (public, private, academic, community, citizen) that seeks a greater benefit for society than for the entity that developed or financed the solution, and is developed and implemented by means of horizontal relationships between the entity that provides the solution and the community that receives it." (Villa, \& Melo, 2015, p.4).

\section{Systems Theory and Innovation Networks}

The authors (Carayannis, Campbell, \& Rehman, 2016) demonstrate a theoretical relationship between systems theory and innovation networks. The elements of systems theory may be identified with the nodes in an innovation network, and the relationship that forms between innovation nodes is similar to the relationships that form between the elements of a system. The incorporation or elimination of nodes within an innovation network, or a change in the relationship between two or more nodes, may be assimilated to a development in time, which is an important characteristic of systems theory (Forrester, 1995; Abatecola, 2014).

\section{Innovation Hub}

Three (3) types of definitions exist for the concept of an innovation hub. The first is associated with regional innovation hubs (Florida, 1995) and is related to the integration of local and external allies who are interested in the development of the region, including the university, NGOs, businesses, and government; another definition of the concept is related to the understanding of the university as an innovation hub that integrates other agents under its leadership into the activities it carries out (Youtie \& Shapira, 2008); a final definition of innovation hub is that of a small physical location with meeting spaces, technological support, and specific characteristics that promote social innovation (Toivonen \& Friederici, 2015), technological entrepreneurship (InfoDev, 2014), business innovation (Bell, Fletcher, Greenhill, Griffiths, \& McLean, 2014; Wire, York, \& York, 2016) or the development of prototypes (Gascó, 2017).

\section{Technology Hubs and/or Social Innovation}

A specific type of small-scale, specialized, technology-based hub has appeared in Africa and a few other regions in the world during the last several years and has demonstrated great potential for entrepreneurship and innovation (Littlewood \& Kiyumbu, 2017). This type of hub meets the need for spaces that may serve as locations for meeting, community development, and the creation of new commercial products (GIZ, 2013).

An innovation hub consists of a small physical space with a wireless internet connection that is furnished with desks, chairs, conference tables, and portable computers. This space is used for presentations, events, follow-up sessions, and small creative competitions (Toivonen \& Friederici, 2015) such as hackathons (Pogačar \& Žižek, 2016). "The first organization having these characteristics that define technology and/or social innovation hub was the London Hub, founded in 2005. Another type of Hub exhibiting these characteristics has developed in Africa-the Nairobi iHub, founded in 2010, an organization that has most extensively used the term "Hub." The London Hub has been emulated around the world, pioneering the creation of a network of such organization, whereas iHub has been used as a model by independent African organizations" (Friederici, 2016).

Other versions of technological or innovation hubs exist, such as those created by technology companies or in partnership with governments and international organizations (infoDev, 2014) or else those that use different terminology, such as the Living Labs (Gascó, 2017). In addition, some private businesses such as Red Hat use them to promote their business model (Wire et al., 2016).

\section{Illustration}

\section{Proposal for Hub-based University Innovation Model}

This conceptual study is based on the theoretical approaches of systems, fractal knowledge networks (Carayannis et al., 2016), open innovation (Johannsson et al., 2015), regional innovation ecosystems, triple helix models, and quadruple helix models (Carayannis \& Campbell, 2009; Sarpong et al., 2015). The model will be made up of various subsystems that interact among themselves. These subsystems are formed by a specialized network of technological or social innovation hubs (See Figure 1). Thus, a subsystem may contain fractal-type characteristics (Carayannis \& Campbell, 2009) and be made up of other subsystems. The fractal shown in Figure 1 is called the "Sierpinski carpet” (Moreno-Marín, 2002, p.97). The subsystems agglutinate various topics of interest for the university community, whether they are put forward by the university itself or by external agents such as the government, businesses, NGOs, or any other regional, national, or international agencies.

Figure 1. The University is Seen as a Hub Network System with Fractal Characteristics

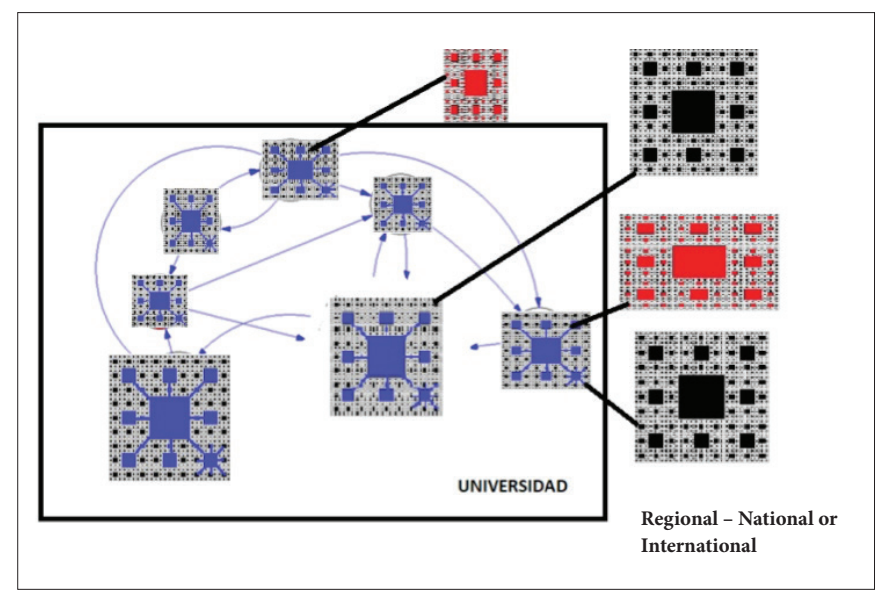


The Hubs facilitate communication among businesses, governments, communities, funders, and other external agents as well as among internal agents, such as professors, students, and administrative staff of the university, thus allowing for the joint creation of knowledge in the form of open innovation (Johansson et al., 2015). As may be seen in Figure 1, each hub may connect with internal and external agents in an autonomous and/or cooperative manner, and with other Hubs. This characteristic flexibility of these innovation hubs allows them to participate in various systems of external innovation networks, incorporating agents that are outside the university.

The type of Hub considered in this work possesses characteristics that are most similar to those of a technological and/or social innovation hub (Friederici, 2016), and it will be referred to as a MicroRegionalHub.

The MicroRegionalHub for innovation will be defined as a unit that agglutinates knowledge concerning a social problem found in the region (Hunger, Limited access to water, Transportation, Flooding, Inclusion, etc.) for which a solution may be sought through diverse interdisciplinary projects that involve students, professors, or university administrative staff, but which also allow for simultaneous participation by external agents that are interested in the topic. A MicroRegionalHub such as the one being proposed must be created (or activated) easily by the interest of an agent (whether from within or without the institution) and shut down (or deactivated) without too much trouble when interest in the topic has waned or when it becomes necessary to incorporate it into another hub. It should be noted that this type of innovation hub is flexible, allowing it to evolve and adapt to changing environments and to the presence or absence of interest on the part of agents both within and outside the university. Another advantage that this model brings to the university is its capacity to agglutinate knowledge and make it available for use by agents both internal and external to the institution, providing a purpose and interdisciplinary quality to the university. According to this conceptual model, the characteristics of a MicroRegionalHub will now be defined.

\section{Characteristics of a MicroRegionalHub}

A MicroRegionalHub must take into account the following three (3) characteristics: Structure, Operation, and Connections. See table 1

Table 1. Characteristics of a MicroRegionalHub

\begin{tabular}{l|l|l}
\hline Characteristics & Parts & \\
\hline \multirow{4}{*}{ Structure } & Design & \\
\cline { 2 - 3 } & \multirow{3}{*}{ Platforms } & Administrative \\
\cline { 3 - 3 } & & Virtual laboratories \\
\cline { 2 - 3 } & Prototypes & \\
\cline { 2 - 3 } Operation & & Café \\
\cline { 3 - 3 } & \multirow{4}{*}{ Methodologies } & Agile \\
\cline { 3 - 3 } & & Hackathon \\
\cline { 3 - 3 } & & Gamification \\
\cline { 2 - 3 } & & Crowdsourcing \\
\cline { 2 - 3 } & & Crowdfunding \\
\hline \multirow{2}{*}{ Connections } & Internal & \\
\cline { 2 - 3 } & External & \\
\hline
\end{tabular}

The concept of "structure" includes two components-design and platforms. A MicroRegionalHub must have a design that is similar to that used by the technology and social innovation hubs described above, that is, it must be small and comfortable and must be decorated in a way that encourages motivation, communication, and focus on the topic to be dealt with. Its location must be taken into account in order to be compatible with the culture of its surroundings. To the extent that is possible, the hubs must be capable of being installed, moved, or dismantled quickly and easily. The second component of the structure is that which has been called "platforms." Each hub must have, as a minimum technological support (or platform), a wireless high-speed internet connection. In addition to this basic technology, other forms of technology are required that allow for coordination of the group of people who work at the hub and increase their productivity. One example of such technologies is Trello (https://trello. $\operatorname{com} /$ ), which makes use of agile teamwork methodologies. Examples of other forms of technologies or platforms such as virtual or remote laboratories (Sánchez, Gómez-Estern, \& Muñoz De la Peña, 2012) are very useful in allowing the hubs to maintain communication. Finally, in areas pertaining to technological or platform support, the MicroRegionalHubs must possess technology that is geared toward structuring the information they generate, an example being that of massive open online courses, known as MOOC (Baturay, 2015), which make possible the compilation, dissemination, and appropriation of knowledge by Hub participants.

Another characteristic of the MicroRegionalHub must also be taken into account, namely, the manner in which they are to operate and the manner in which their tasks are to be carried out. The functioning or operation of the MicroRegionalHubs must be grounded in both the development of prototypes (Deininger, Daly, Sienko, \& Lee, 2017) and in work methodologies that incorporate open innovation. The MicroRegionalHubs must provide an atmosphere of camaraderie and gamification that allows for the generation of collective ideas, in addition to taking into account the generation of prototypes and the procurement of resources for this purpose.

Six (6) methodologies have been selected for use in a MicroRegionalHub, all of which are currently in frequent use; two (2) of these allow for the generation of innovative ideas in a collective manner (café (http://www.theworldcafe.com/) and crowdsourcing (Johannsson et al., 2015)), two (2) others allow for the rapid generation of prototypes (agile (Campanelli \& Parreiras, 2015) and hackathon), a further methodology is based on the principle of gaming (gamification (Morschheuser, Hamari, Koivisto, \& Maedche, 2017)), and the final methodology aids the financing of prototypes ("crowfounding" (Morschheuser et al., 2017, p.27)).

The third characteristic of a MicroRegionalHub is related to the manner in which it makes both external and internal connections. Although these connections are based on technological characteristics, as in the case of remote laboratories they are related to topics associated with the methods or mechanisms used for the physical exchange of persons and take into account other factors, such as legal, cultural, and economic factors. This third characteristic is foundational for implementing 
flexibility and open innovation in a hub, since the desire to move and participate in another hub must be fostered among hub members, therefore requiring a manner in which this may be accomplished quickly and easily. This characteristic must ensure that the hub members can be mobile and promote participation of foreigners in order to create a culture of exchange in the MicroRegionalHub.

\section{Innovation Initiatives of the University of Magdalena About the University of Magdalena}

"The University of Magdalena is a state institution of a territorial nature, created by Law No. 005 from October 27 1958, organized as an autonomous institution under special circumstances, related to the Ministry of National Education with relation to policy and planning within the educational sector. It possesses a legal personality, which was conferred by Resolution 831 of the Departmental Government of Magdalena on December 3, 1974. Its purpose is to provide the public service of higher education by exercising its academic, administrative, financial, and budgetary autonomy, with its own independent government, income, and patrimony. It is governed by the Political Constitution according to Law 30 from 1992, as well as the remaining applicable legal provisions in accordance with its special circumstances and the norms that are dictated in the exercise of its autonomy." (http://www.unimagdalena.edu.co/Institucional/Paginas/Historia. aspx). The university is located in the city of Santa Marta, Department of Magdalena, Colombia.

The university currently has an administrative plan for the period 2016-2020 whose goal is to become the most inclusive and innovative university, expressed according to the following governing principles: "Our proposal is based on a diagnostic plan formulated by professors and students in a participative manner, the examination of successful cases of university management, and the foundations of the enterprising or third-generation university (3GU). The proposal is structured according to two complementary perspectives: the mission axes of teaching, research, extension, and their supporting processes, and a group of policies that are geared toward institutional development. The principles for developing this university model are as follows: leadership, orientation toward innovation, academic rigor, social and environmental responsibility, a high sense of relevance, shared governability, transparency, and results-oriented management." (http://www.unimagdalena.edu.co/Institucional/Paginas/PlanGobierno2016-2020.aspx)

The transition toward a third-generation university (3GU) model requires strategic planning and adequate change management. The 3GU model implies new forms of teaching, organization, and financing (Wissema, 2009). The innovation model based on hub may contribute significantly to all characteristics of the $3 \mathrm{GU}$ model, but it is especially useful in forwarding the organizational transformation.

The University of Magdalena is currently organized into six (6) schoolsengineering, health, humanities, education, business, and basic science; by the year 2020 it should have already made progress in the transformation toward centers and institutes that strengthen interdisciplinarity and transdisciplinarity, which in turn should boost the activities of research, entrepreneurship, and innovation. (http://www.unimagdalena.edu.co/ Institucional/Paginas/Estructura-Organizacional.aspx)

Various initiatives and innovation activities have begun to take place in the university in order to fulfill its management plans, such as the adoption of agile work methodologies, the design of spaces for innovation, and the use of software to aid in the administration of the tasks that the university work groups must carry out. Table 2 summarizes these initiatives according to the framework of the proposed model.

Table 2. Some of the activities carried out by the University of Magdalena, examined according to the proposed model

\begin{tabular}{l|l|l|l}
\hline \multirow{2}{*}{ Structure } & Design & & X \\
\cline { 2 - 4 } & \multirow{4}{*}{ Platforms } & Administrative & X \\
\cline { 3 - 4 } & & Virtual laboratories & \\
\cline { 3 - 4 } Operation & Prototypes & MOOC & \\
\cline { 3 - 4 } & \multirow{4}{*}{ Methodologies } & Café & \\
\cline { 3 - 4 } & & Ágile & Xackathon \\
\cline { 3 - 4 } & & Gamification & \\
\cline { 3 - 4 } Connection & Internal & Crowdsourcing & \\
\cline { 3 - 4 } & External & Crowdfunding & X \\
\hline
\end{tabular}

During the year 2017, the university planning office led the innovation initiatives, using as a reference the proposed model, which has served as an aid in its carrying out the current management plan.

\section{Method}

For this conceptual study, an initial literature review of innovation models was conducted. The question that guided the search was as follows: What is an adequate innovation model for a regional university such as the University of Magdalena? The Google Scholar search engine was used to conduct this search, and as a result, deliver the doctoral thesis "Innovation hubs in Africa: Assemblers of technology entrepreneurs" (Friederici, 2016). This thesis was relevant to the goal of this study and therefore was used as the main reference. Based on the information from this doctoral thesis and using the search question as a reference, a second review of the literature was conducted in the Scopus database using keywords such as open innovation, systems, fractal, knowledge networks, hub, social innovation, university, regional development, innovation ecosystems, and models. The resulting documents were then ranked according to the number of citations, and a filter was applied for those that were most cited. Another filter was applied by reading the article abstracts and choosing those that were relevant to the initial search question, after which the articles published in the 
journals of highest impact were identified using the scimago platform (http://www.scimagojr.com/). This information was complemented with other searches for documents, websites, and doctoral theses.

\section{Discussion and Conclusions}

The objective of the conceptual study was to develop an initial proposal for a regional innovation model for the University of Magdalena, based on small technological and social innovation units known as hubs, which are already in operation in various parts of the world, especially in Africa. The model consists of hub networks that allow for open innovation to be promoted by the university, which due to its fractal characteristics possesses greater flexibility that allows it to adapt to changes in the environment and more easily become integrated into the regional innovation ecosystem.

This model is envisioned as an alternative to university innovation models that are based on the overall perspective of business, government, and university, which hinders their implementation in areas having weak relations with the government and a scarce entrepreneurial base. This new model facilitates the utilization of the available social potential of these regions.

The characteristics of an innovation hub that are suitable for a regional university innovation model are described and referred to as a MicroRegionalHub, and it is shown how the innovation initiative currently being carried out by the University of Magdalena might be understood according to this framework.

\section{Future Research}

This conceptual study will serve as an initial reference for the research project being conducted by the primary author in order to develop a system model for innovation in regional universities. The short-term suggestion is to conduct case studies in regional universities that may serve as input for the elaboration of a general innovation model that they may implement. The medium-term plan is to verify progress in the innovation models of regional universities that use the elaborated theoretical model as a reference. Further research that may be carried out includes measuring the impact that the university's mission tasks may have on this type of innovation model.

\section{References}

Abatecola, G. (2014). Research in organizational evolution. What comes next? European Management Journal, 32(3), 434-443. https://doi. org/10.1016/j.emj.2013.07.008

Baturay, M. H. (2015). An overview of the World of MOOCs. Procedia - Social and Behavioral Sciences, 174, 427-433. https://doi. org/10.1016/j.sbspro.2015.01.685

Bell, F., Fletcher, G., Greenhill, A., Griffiths, M., \& McLean, R. (2014). Making MadLab: A creative space for innovation and creating prototypes. Technological Forecasting and Social Change, 84, 43-53. https:// doi.org/10.1016/j.techfore.2013.09.004
Campanelli, A. S., \& Parreiras, F. S. (2015). Agile methods tailoring A systematic literature review. Journal of Systems and Software, 110, 85-100. https://doi.org/10.1016/j.jss.2015.08.035

Carayannis, E. G., \& Campbell, D. F. J. (2009). "Mode 3" and "Quadruple Helix": Toward a 21st-century fractal innovation ecosystem. International Journal of Technology Management, 46(3-4), 201-234. https://doi.org/10.1504/IJTM.2009.023374

Carayannis, E. G., Campbell, D. F. J., \& Rehman, S. S. (2016). Mode 3 knowledge production: systems and systems theory, clusters and networks. Journal of Innovation and Entrepreneurship, 5(1), 17. https:// doi.org/10.1186/s13731-016-0045-9

Dedehayir, O., Ortt, J. R., \& Seppänen, M. (2017). Disruptive change and the reconfiguration of innovation ecosystems. Journal of Technology Management \& Innovation, 12(3), 9-21. https://doi.org/10.4067/ s0718-27242017000300002

Deininger, M., Daly, S. R., Sienko, K. H., \& Lee, J. C. (2017). Novice designers' use of prototypes in engineering design. Design Studies, 51, 25-65. https://doi.org/10.1016/j.destud.2017.04.002

Florida, R. (1995). Toward the learning region. Futures, 27(5), $527-$ 536. https://doi.org/10.1016/0016-3287(95)00021-N

Forrester, J. W. (1995). Counter-intuitive behavior of social systems. Recovered from https://ocw.mit.edu/courses/sloanschool-of-management/15-988-system-dynamics-self-study-fall1998-spring-1999/readings/behavior.pdf

Friederici, N. (2016). Innovation Hubs in Africa: Assemblers of Technology Entrepreneurs, (October). retrieved from http://cii.oii.ox.ac. uk/wp-content/uploads/sites/38/2017/05/Friederici-thesis-AbstTOC-Jan-2017.pdf. https://doi.org/10.2139/ssrn.3123840

Gascó, M. (2017). Living labs: Implementing open innovation in the public sector. Government Information Quarterly, 34(1), 90-98. https://doi.org/10.1016/j.giq.2016.09.003

GIZ. (2013). Technology Hubs - Creating space for change: Africa's technology innovation hubs. retrieved from : http://10innovations. alum niportal.com/technology-hubs.html? ut m _ content=buffer60fb8\&utm_medium =social\&utm_source $=$ twitter. com\&utm_campaign=buffer

InfoDev. (2014). The Business Models of mLabs and mHubs. Retrieved from http://www.infodev.org/infodev-files/mlab_and_mhub_publication_0.pdf

Johannsson, M., Wen, A., Kraetzig, B., Cohen, D., Liu, D., Liu, H.... Zhao, Z. (2015). Space and Open Innovation: Potential, limitations, and conditions of success. Acta Astronautica, 115, 173-184. https:// doi.org/10.1016/j.actaastro.2015.05.023 
Littlewood, D. C., \& Kiyumbu, W. L. (2017). "Hub" organisations in Kenya: What are they? What do they do? And what is their potential? Technological Forecasting and Social Change https://doi.org/10.1016/j. techfore.2017.09.031

Martin-Sardesai, A., Irvine, H., Tooley, S., \& Guthrie, J. (2017). Organizational change in an Australian university: Responses to a research assessment exercise. The British Accounting Review, 49(4), 399-412. https://doi.org/10.1016/j.bar.2017.05.002

Molina, C., Polanco, J., \& Montes, J. (2015). Foundations for governing the area of science, technology, and innovation in Medellín, Colombia. Semestre Económico, 18(38), 191-213. https://doi.org/10.22395/ seec.v18n38a7

Moreno-Marín, J. C. (2002). Didactic experience in Mathematics: constructing and studying fractals. IDEAS Y RECURSOS, 91. https:// www.researchgate.net/publication/39220593_Experiencia_didactica_en_Matematicas_construir_y_estudiar_fractales

Morschheuser, B., Hamari, J., Koivisto, J., \& Maedche, A. (2017). Gamified crowdsourcing: Conceptualization, literature review, and future agenda. International Journal of Human-Computer Studies, 106(March 2016), 26-43. https://doi.org/10.1016/j.ijhcs.2017.04.005

Novoa, A. C. (2016). Scientific-technological innovation in IberoAmerican universities. Journal of Technology Management and Innovation, 11(4), 1-4. https://doi.org/10.4067/S0718-27242016000400001

Pogačar, K., \& Žižek, A. (2016). Urban hackathon - Alternative information based and participatory approach to urban development. Procedia Engineering, 161, 1971-1976. https://doi.org/10.1016/j. proeng.2016.08.788

Rao-Nicholson, R., Vorley, T., \& Khan, Z. (2017). Social innovation in emerging economies: A national systems of innovation-based approach. Technological Forecasting and Social Change, 121, 228-237. https://doi.org/10.1016/j.techfore.2017.03.013

Salazar, P. H. V. (2015). Organizational factors as determiners of the impact of cooperation with businesses - A study in Latin American universities. Complutense of Madrid. (Doctoral dissertation, Universidad Complutense de Madrid). Recovered from: http://eprints.ucm. es/40850/1/T38263.pdf
Sánchez, C., Gómez-Estern, F., \& de la Peña, D. M. (2012). A virtual lab with automatic assessment of nonlinear controller design exercises. IFAC Proceedings Volumes, 45(11), 172-176. https://doi. org/10.3182/20120619-3-ru-2024.00080

Sarpong, D., AbdRazak, A., Alexander, E., \& Meissner, D. (2015). Organizing practices of university, industry, and government that facilitate (or impede) the transition to a hybrid triple helix model of innovation. Technological Forecasting and Social Change, 123, 142-152. https://doi.org/10.1016/j.techfore.2015.11.032

Toivonen, T., \& Friederici, N. (2015). Time to define what a "hub" really is. Stanford Social Innovation Review, 1-37. retrieved from https://ssir.org/articles/entry/time_to_define_what_a_hub_really_is

Villa, L., \& Melo, J. (2015). A current overview of social innovation in Colombia. Banco Interamericano de Desarrollo, 81. https://doi. org/10.18235/0000004

Youtie, J., \& Shapira, P. (2008). Building an innovation hub: A case study of the transformation of university roles in regional technological and economic development. Research Policy, 37(8), 1188-1204. https://doi.org/10.1016/j.respol.2008.04.012

Wire, B., York, N., \& York, N. (2016). Red Hat Launches Red Hat Open Innovation Labs, Introducing Collaborative Open Source Cloud and DevOps Residency Program, 1-4. Retrieved from: https://www. redhat.com/en/about/press-releases/red-hat-launches-red-hat-openinnovation-labs-introducing-collaborative-open-source-cloud-anddevops-residency-program

Wissema, J. G. (2009). Towards the third-generation university: Managing the university in transition. Edward Elgar Publishing. https://doi. org/10.4337/9781848446182

https://trello.com/ [Accessed: March 27, 2018]

http://www.theworldcafe.com/ [Accessed: March 27, 2018]

http://www.unimagdalena.edu.co/Institucional/Paginas/Historia. aspx [Accessed: March 27, 2018]

http://www.unimagdalena.edu.co/Institucional/Paginas/PlanGobierno2016-2020.aspx[Accessed: March 27, 2018]

http://www.unimagdalena.edu.co/Institucional/Paginas/EstructuraOrganizacional.aspx[Accessed: March 27, 2018] 
